\title{
Use of technology as an adjunct to improve health outcomes for survivors of cancer
}

\author{
E.-L. Laakso ${ }^{1,2}$, J. Tandy ${ }^{1}$
}

${ }^{1}$ School of Physiotherapy and Exercise Science, ${ }^{2}$ Griffith Institute of Health and Medical Research, Griffith University, Gold Coast, Qld, Australia

Background: In a time of increasing use of eHealth technologies, it is appropriate to consider how these might be used in physiotherapy for improving health outcomes for survivors of cancer.

Objectives: The aim of this paper was to understand what technologies are in use in health care and how technologies are being used in cancer care and rehabilitation. Further, to consider the benefits and potential disadvantages of technologies in the field of oncology.

Major findings: Two eHealth strategies used for education and intervention were considered: web-based and convergence technologies (the union of web-based and mobile technologies). To date, the use of webbased eHealth technologies for educating survivors of cancer is more advanced than the use of convergence methodologies which may be more suited to health care interventions. The benefits for geographically isolated populations and for information dissemination are evident. A number of challenges remain, in particular the rapid development of interactive technologies, and the reliability of, and secure access to information for intervention trials.

Conclusions: The use of eHealth technologies should be incorporated in cancer rehabilitation; however, it is as yet too early to substitute such technologies for traditional methods.

Keywords: Cancer care, eHealth, Physiotherapy, Rehabilitation, Technology

\section{Background}

In Australia, according to the most recent available data, by the age of 75 years, one in three males and one in four females will have been diagnosed with cancer at some stage of their life. ${ }^{1}$ The risk increases with age to one in two for males and one in three for females. ${ }^{1}$ Worldwide, cancer accounted for $13 \%$ of all deaths in 2004 yet a third of all cancers are preventable. $^{2}$ According to the World Health Organization (WHO):

\begin{abstract}
'Knowledge about the causes of cancer, and interventions to prevent and manage the disease is extensive. Cancer can be reduced and controlled by implementing evidence-based strategies for cancer prevention, early detection of cancer and management of patients with cancer. ${ }^{2}$
\end{abstract}

While there has been an increase in the incidence of cancer diagnoses, the death rates in some cancers are slowing, reflecting improvement in the medical and surgical management of patients with cancer, at least in developed countries. It is suggested that advances in cancer treatment will result in it becoming a manageable chronic disease, reflected in the inclusion of cancer

Correspondence to: E L Laakso, School of Physiotherapy and Exercise Science, Griffith University, Gold Coast, Qld 4222, Australia. Email: l.laakso@griffith.edu.au in the WHO action plan for the global strategy for the prevention and control of non-communicable diseases. ${ }^{3}$ Ironically, improvements in cancer treatment mean that it is now recognized that survivors of cancer are not only at increased risk of developing secondary cancers but also at increased risk of developing chronic diseases, notably cardiovascular disease and diabetes. ${ }^{4}$ There also remains significant morbidity associated with the disease and its treatment. Approximately 30\% of all cancer survivors report decreased quality of life due to physical and psychosocial problems following cancer diagnosis and treatment. $^{5}$

As an addition to conventional medical treatments, exercise and diet modifications have been associated with improving outcomes in people with cancer. ${ }^{6}$ There is increasing evidence to suggest that outcomes may be optimized by interventions that emphasize physical activity, maintenance of body mass index, and limited ingestion of energy-dense foods and drinks (especially alcohol), all of which have 'convincing' and 'probable' causal associations with many cancers. ${ }^{6}$ Research suggests that there is significant demand for lifestyle interventions. A study of the assessment of rehabilitation needs in patients with cancer $^{5}$ revealed that the primary desire of survivors 
of cancer is to have access to rehabilitation programmes that focus on diet, physical capacity, and psychosocial support. Barriers to these programmes may be both geographical and socioeconomic and are reflected in relative survival rates. ${ }^{7}$

Brenner ${ }^{8}$ suggests that patients most recently diagnosed with cancer (compared to those diagnosed many years ago) have very favourable long-term survival prospects. The challenge appears to be how to harness improvements in screening, medical and surgical care, and lifestyle modifications to optimize quality of life and the rehabilitation of survivors of cancer, and to facilitate sustainable outcomes. EHealth technologies may be one such methodology. This paper provides a definition for eHealth, discusses the evolution of webbased and mobile technologies increasingly being used in eHealth, and reviews some of the ways in which eHealth is contributing to improved health outcomes in general, and for survivors of cancer more specifically. The limitations and future prospects of eHealth technologies are outlined.

\section{EHealth - What Is It?}

The WHO defines eHealth as "the combined use of electronic communication and information technology in the health sector'. ${ }^{9}$ EHealth encompasses a range of technologies including telemedicine (and its various off-shoots such as telerehabilitation and telegenetics), electronic health records, health information systems, mobile health, consumer health informatics, virtual health care systems, and decision support systems, to name a few. Each is characterized by its target audience (e.g. consumers, health professionals) and the use of cyberspace more broadly. There is now common acceptance of the classification of web-based systems such that the original Web 1.0 was 'mostly unidirectional, whereas Web 2.0 allows the user to add information or content to the web, thus creating interaction'. ${ }^{10}$ Web 2.0 technologies include social media tools for social networking and online communities, and are being considered as potential health enablers. The combination of webbased technologies and health care has in turn generated the term Medicine 2.0 which is inclusive of collaboratives, systems, services, and health information in general. ${ }^{10}$ Such is the pace at which technological change is progressing that Web 2.0 will likely be replaced by Web 3.0 (the semantic web, connecting knowledge) and Web 4.0 (the ubiquitous web, connecting intelligence). ${ }^{11}$

\section{Efficacy of Web-based Technologies for Health Care}

The World Wide Web was created in 1989 to overcome geographical boundaries and to facilitate data sharing. ${ }^{12}$ Since that time, the inclusion of eHealth technologies in health care has steadily progressed. There is evidence to support the potential long-term efficacy of internet-based interventions for promotion of both self-care and health. ${ }^{13-15}$ Such interventions provide the potential for early and perhaps sustained delivery of health information (education) to individuals who previously were not afforded access, and through early intervention (treatment), may assist in long-term compliance with health protocols for those with chronic disease. ${ }^{16,17}$

In a controlled trial of web-based diabetes disease management, ${ }^{18}$ a web-based information management and clinical decision support tool intervention effectively assisted physician time management and patient-practitioner communication, and therefore facilitated increased testing and screening and subsequently, patient outcomes. Wantland et al. ${ }^{14}$ found that web-based interventions for chronic illness patients requiring knowledge sharing, education, and understanding were superior to non-web-based interventions for increasing weekly patient exercise time, nutritional status, participation in health care, 18-month weight loss maintenance and for slowing health decline. In response to research linking diet and chronic illness, Alexander et al. ${ }^{19}$ performed a randomized clinical trial evaluating online interventions to improve fruit and vegetable consumption. Following the intervention period, fruit and vegetable consumption increased significantly and the improvements were closely maintained at 12-month followup. Assessment of frequency of access to the website showed a positive relationship between access frequency and mean daily fruit and vegetable intake.

\section{Web-based Technologies for Cancer Care}

Use of the 'web' to present health-based interventions to survivors of cancer has become a viable option having the capacity to overcome both the socioeconomic and geographical barriers to treatment. ${ }^{5}$ Previous work has identified a range of unmet supportive care needs in patients with cancer and their families including the need for cancer information. ${ }^{20}$ Graham and Abrams ${ }^{21}$ suggest that the 'Internet may be the most important dissemination vehicle to improve individual and overall public health at reasonable societal cost', although by itself it will not reduce the burden of cancer. The authors suggested that the internet should be used as an embedded tool for translating evidence-based health and behaviour research. ${ }^{21}$ Until recently, it has been mainly Web 1.0 capabilities such as online education (information dissemination) that have been investigated, therefore it is reasonable to review how this capability has been used.

\section{Web 1.0 capabilities}

Health outcomes may be maximized by emphasizing patient education and promotion of self-efficacy ${ }^{22,23}$ 
as well as practitioner education. In one of few studies of the efficacy of eHealth in survivors of cancer, of three online behaviours among internet users, Atkinson et al. $^{24}$ found that $58 \%$ of those surveyed used the internet to search for information for their own use and only $3.8 \%$ used online support groups. The users were more likely to be women, under the age of 50 years, white, married, educated, of poorer health status, and in lower income groups, although earlier studies suggest that cultural influences are also likely to be involved. ${ }^{25}$ Gustafson et al. ${ }^{26}$ tested a computer-based patient support system in young women with breast cancer and concluded that computer competence, participation in health care, and confidence in doctors were increased at 2-month followup. Moreover, social support and information competence had increased significantly by 5-month follow-up. Kinnane and Milne ${ }^{27}$ reviewed the literature regarding the use of the internet by cancer carers and concluded that information searching and online forums were also increasingly used by those who care for survivors of cancer.

Murrat et $a .^{28}$ have identified the three most important benefits of web-based interventions (interactive health communication applications) as being the facilitation of superior provision of information to patients, promotion of health behaviours, and management of the burden placed on health services. A discussion of these perceived benefits follows.

\section{Web-based interventions facilitate superior provision of information to patients}

This outcome can be attributed to the provision of large volumes of regularly updated information via userfriendly and easily accessible media. Tailoring of the intervention to a specific population (e.g. survivors of breast cancer) may optimize personal significance and therefore retention of and adherence to information. ${ }^{28}$ In a systematic review and meta-analysis, Gysels and Higginson $^{29}$ found that educational technology was as effective or slightly superior to traditional methods; however, the technology interventions had variable impacts on patient involvement in decision making. Bylund et al. ${ }^{30}$ found that when health care providers validated patient's efforts to find web-based information, patient satisfaction improved and concerns decreased. However, the length of patient-practitioner consultations was found to increase significantly when internet information was discussed. ${ }^{31}$

With the burgeoning of technologies and new systems, and the competitive nature of the information and computer technology industry, developments in the field are rapidly outpacing the ability to institute and integrate technologies into eHealth strategies. In a survey of users, Bright et al. ${ }^{32}$ found that both traditional and technology-based information support was essential in order to bridge the digital divide for underserved populations. The authors reported that $40 \%$ of their sample $(n=6019)$ reported using the internet for information yet only $20 \%$ found the information that they were seeking. Therefore, not only is the technology itself at issue, so is the content and its quality. ${ }^{21}$ Methods for determining the quality of web-based content, of empowering consumers on how to identify the veracity of information, and facilitating timely and appropriate access are continuing challenges in this field.

\section{Web-based interventions promote health behaviours} Superior information provision better equips patients to adhere to positive health behaviours, ${ }^{28}$ an important aspect of creating sustainable change and improving long-term survivorship in people who have experienced cancer. A move towards using web-based technologies to collect quality of life data has seen the recognition of issues such as validity, reliability, and costs of the technology. ${ }^{33}$ Many studies fail to address methods of determining the validity of patient-reported health behaviours particularly when interactive components are employed as methods of measuring and reporting behaviourrelated outcomes (such as online survey tools). Restricting an individual to a desktop personal computer seems counter-intuitive if the individual is required to regularly enter data on behaviours such as physical activity. More dynamic technologies may be more suitable for such endeavours. Hesse et al. ${ }^{34}$ stress the need for a user-centerd approach to health information technology. The authors suggest that adoption rates of eHealth can be improved and thus benefits optimized by ensuring that stakeholders can influence technology design and utility, so making technologies maximally productive in supporting effective communication and intervention.

\section{Web-based interventions manage burden placed on health services}

As a result of information provision to cancer survivors, communication skills between patients and health professionals may be optimized, resulting in more efficient patient tracking, health care provision, improved patient outcomes, decreased time spent with health care providers, containment of costs and therefore, a reduction in the burden placed on health services. ${ }^{28,35-37}$ In a study of telehealthbased cancer genetic counselling (telegenetics), ${ }^{38}$ women with hereditary breast and/or ovarian cancer and with low psychosocial needs, reported high levels of acceptance and convenience with the service provided. The authors suggested that where more complex psychosocial issues may be involved, additional strategies would be required to support these 
women. The opinions of the geneticists were not evaluated in the study.

\section{Limitations of Web 1.0 technologies}

In a review of eHealth communication issues, Neuhauser and Kreps ${ }^{39}$ have confirmed recently what many have long suspected: the efficacy of health information technologies for promoting sustainable, positive lifestyle behaviour change is 'painfully slow' and in some cases worse than ever. In previous work, the same authors identified that although online cancer communication can enhance efforts to reach diverse audiences, thus improving knowledge and behaviours, online methods have not met the needs of those with low literacy levels or those from culturally and linguistically diverse (non-Englishspeaking) populations. Research in other areas of health care supports these findings, ${ }^{18}$ with particular limitations noted regarding the level of language (i.e. practitioner versus patient), access factors (such as health practitioner time constraints), and health care providers' belief that use of a computer was a barrier to communication with patients. The outcome raised the notion that web-based support tools were ineffective, costly and time-consuming, and led to questioning of whether health consumer behavioural change outcomes could be as effective using web-based versus non-web-based methods.

Further matters of concern are the quality of information found on the internet, how the information is used, and the need to educate patients so they may more effectively evaluate health information. ${ }^{40}$

Many of the criticisms appear to have evolved due to the static nature of Web 1.0 technologies resulting in attempts to use virtual communities and other methods of interactivity to better engage users (Web 2.0). The uptake and understanding of the capabilities of Web 2.0 technologies by health practitioners is also low. In a recent (unpublished) survey by Usher, of 935 Australian allied health practitioners, $71.3 \%$ did not use Web 2.0 at all, with $83.3 \%$ citing a lack of understanding of Web 2.0 as a reason for not adopting the technology as a way of delivering health care. While one in five used Web 2.0 for personal needs, evidently the potential for its use in the professional sphere has not been realized.

\section{Convergence Technologies}

One solution to issues of accessibility and to the static nature of web-based (Web 1.0) technologies has been to increase flexibility, utility, and mobility. Interactivity of eHealth technologies has been enhanced by mobile information technologies and Web 2.0 capabilities. The union of web-based and mobile technologies has been termed 'convergence technologies'. Usher ${ }^{41}$ identifies four interactive components or capabilities that are increased through the inclusion of Web 2.0 convergence technologies, these being (1) multimodality; (2) networkability; (3) temporal flexibility; and (4) message tailoring capabilities. Recent examples of convergence technologies are the third generation (3G) mobile and smart telephones, and the imminent $4 \mathrm{G}$ (Beyond 3G) broadband telephone. According to a United Nations report, worldwide cell (mobile) telephone usage has reached $60 \%$ (compared to $12 \%$ in 2000 ) and $64 \%$ of mobile telephone users are found in the developing world. ${ }^{42}$ The uptake of mobile technologies is such that static points of online access are fast becoming redundant, and dynamic mobile platforms are rapidly overtaking communication methods such as email.

The development, testing, and use of mobile technologies for health behaviour change have increased in recent years with the advent of smart phones incorporating gyroscopes, accelerometers and global positioning sensors, and the ability of consumers to develop applications ('apps' also known as widgets) for mass dissemination via technology conglomerates. The convergence of Web 2.0 and mobile technologies has coincided with the development of social media (including blogging and networking sites) that are almost exclusively the domain of younger cohorts. Chou et al. ${ }^{43}$ report a statistically significant linear relationship with younger age groups reporting greater use of social media, as well as greater use by those with poorer subjective health status. Moreover, use of social media was independent of education, ethnicity, or health care access. Those who had a personal experience with cancer were more likely to have participated in an online support group. ${ }^{43}$

In an early study of a wireless (mobile telephone) health outcomes monitoring system to improve communication between cancer patients and the healthcare team, Bielli et al. ${ }^{44}$ noted that a significant percentage of users $(42 \%)$ refused to use the system. In a more recent study, Maguire et al. ${ }^{45}$ tested the perceptions of nurses towards a mobile telephone-based system to support patients with cancer at home, and found that overall perceptions were positive with recognition of the benefits for early intervention. With the increasing use of mobile technologies, perhaps the older community-dweller who is more likely to use a mobile telephone than the internet, will more easily convert to convergence technologies.

Although little evidence is available for survivors of cancer, convergence technologies have begun to transform health service delivery. Specific advantages include increased access to healthcare and timelier public health information, improved diagnostic and tracking capabilities, and improved access to education and training for health workers. ${ }^{42}$ One of the significant advantages of convergence technology is 
its wireless capability thus setting the consumer free from the desktop personal computer. Conversely, one of the challenges in convergence technologies is to successfully incorporate them with those technologies that will link seamlessly to new health informatics systems (including health records). A host of healthcare projects in developing nations is testament to the penetration of eHealth technologies globally, and their potential for hard-to-reach populations. The ubiquity of mobile devices in the developed world suggests that eHealth service provision for survivors of cancer is a looming reality.

As Kreps and Neuhauser ${ }^{46}$ so elegantly stated:

'eHealth information that is interactive, interoperable, personally engaging, contextually tailored, with the ability to be delivered to mass audiences can really make a difference in enhancing the quality of health care and health promotion efforts. It can reach diverse audiences with information that matches their health needs and communication orientations. Health information can be easily updated and adapted to changing health conditions. It can foster greater participation between interdependent health care providers and consumers and insure that all crucial stakeholders in the health care enterprise have access to timely and accurate information to guide their decisions.'

Tailored interventions (e.g. those that afford participants access to interactive facilities for selfmonitoring, monitoring by health practitioners, individualized feedback, and telephone communication) may be more effective in engaging participants, building their self-efficacy, and improving their adherence with recommended health behaviours than programmes that present only generic educational information. ${ }^{47-49}$ Computer-based interventions that afford patients timely access to educational and interactive tools are indicated for use with behaviours that require regular input to elicit and maintain selfregulation $^{50,51}$ such as dietary and physical activity behaviours.

\section{Limitations of convergence technologies}

Demiris $^{52}$ reviewed the use of virtual communities in health care for increasing patient empowerment, and enhancing coordination of care. Virtual communities were noted in health care delivery teams, research teams, and patient-care-giver applications. Examples of several virtual communities were described with a number of concerns raised including: the progressive dehumanization of interpersonal relationships, potentially negative communications (non-interactivity and hostility), and factors related to identity and deception thus making the experiences potentially counter-productive to those involved. Other drawbacks identified by Demiris ${ }^{52}$ were those related to usability and accessibility of the technologies - what some would describe as the digital divide. The latter is likely to be the greatest drawback to the potential of
eHealth in facilitating sustainable change in consumer-centric systems.

A number of limitations need to be overcome to establish the place of Web 2.0 and convergence technologies as adjuncts to improve outcomes for survivors of cancer. Such factors include obtaining objective data to verify intervention outcomes, the use of interactive tools with known reliability and validity for data evaluation, and the ability to obtain participant feedback or identify issues relating to compliance and intervention efficacy. The inclusion of appropriate interactive components for engaging patients within cyberspace may contribute to improved intervention efficacy, as would the inclusion of remote/wireless applications for monitoring and tracking outcomes.

\section{Limitations of EHealth for Survivors of Cancer}

In addition to the technology-specific factors already noted, a number of other factors impose limits on the capacity of eHealth to improve outcomes for survivors of cancer.

Despite improved survival rates, survivors of cancer may be confronted by psychosocial factors associated with the diagnosis including the possibility of relapse or recurrence. Although there is little scientific basis for the belief that coping styles influence event-free survival, ${ }^{53}$ there is clear evidence that psychological interventions are effective in reducing distress and promoting adjustment in patients with cancer. ${ }^{54}$ Jones et al. ${ }^{55}$ found that participants who received personalized information were less anxious than those who received general computer-based information at 3-month follow-up although participant satisfaction was improved in the technology arm of the trial. As with many other interventions, effective psychological screening and care via eHealth modalities is yet to be established.

The quality of practitioner-patient interactions has not been explicated in numerous studies and data are often based upon patient self-reports. Few if any studies have reported factors based on information security or privacy and with push-pull factors evident (e.g. in Australia) for electronic health records much work needs to be undertaken to manage the competing factors of the requirement for high-grade information and the requirement for secure information systems. And as with all interventions, if the consumer does not use the technology then the potential for sustainable change is negated and no better than that which is attainable by more traditional means.

Lastly, the matter of ethical and confidential patient-practitioner relationships in the absence of face-to-face communication must be addressed. Updated guidelines on these matters are required as health care moves to more remote interactions. 


\section{Implications and Future Directions}

The authors suggest that survivors of cancer may benefit from disease/cancer-specific web-based and convergence technologies that educate and provide feedback regarding healthy lifestyle interventions but the evidence to support this assertion remains scarce. In addressing the issue of eHealth research, a number of associated methodological limitations need to be overcome to establish the place of Web 2.0 and convergence technologies as an adjunct to improve outcomes for survivors of cancer. Few trials of health interventions in the field of cancer care have been conducted entirely online. Murray et al. ${ }^{56}$ make a number of suggestions to optimize eHealth research among them being rigorous design features (e.g. lockout methodologies to prevent multiple access), well-planned recruitment strategies, effective randomization, and verification of identities and participant data, which can be subverted in cyberspace without careful systems design and monitoring. Given that direct costs of cancer intervention have increased (e.g. more than twofold in the USA between 1990 and 2008) ${ }^{57}$ methods for promoting health outcomes for those who survive cancer would appear to be required in order to justify the costs. EHealth technologies may present a solution.

\section{Conclusion}

It is now commonly regarded that 'eHealth technologies will likely play an important role in the evolution of health care, ${ }^{58}$ Web-based information dissemination and convergence technologies hold promise for reducing the burden of care and improving health outcomes. The evidence for integrating eHealth technologies into mainstream cancer care and rehabilitation is not adequately advanced, nor have the limitations been suitably addressed. However, the rapid development of convergence technologies suggests that this is only a matter of time.

\section{References}

1 Australian Institute of Health and Welfare. Australia's health 2008. Cat. no. AUS 99. Canberra (ACT): AIHW; 2008.

2 World Health Organization. Cancer [document on the Internet]. 2009 [cited 2010 June 13]. Available from: http:// www.who.int/mediacentre/factsheets/fs297/en/index.html.

3 World Health Organization. 2008-2013 action plan for the global strategy for the prevention and control of noncommunicable diseases [document on the Internet]. 2008 [cited 2010 June 13]. Available from: http://www.who.int/nmh/Actionplan-PC -NCD-2008.pdf.

4 Brown BW, Brauner C, Minnotte M. Noncancer deaths in white adult cancer patients. J Natl Cancer Inst 1993;85:979-87.

5 van Harten WH, van Noort O, Warmerdam R, Hendricks H, Seidel E. Assessment of rehabilitation needs in cancer patients. Int J Rehabil Res 1998;21:247-57.

6 World Cancer Research Fund/American Institute for Cancer Research. Food, nutrition, physical activity, and the prevention of cancer: a global perspective. Washington DC: AICR; 2007.

7 Hewitt M, Herdman R, Holland J, editors. Meeting psychosocial needs of women with breast cancer. Washington DC: The National Academic Press; 2004.
8 Brenner H. Long-term survival rates of cancer patients achieved by the end of the 20th century: a period analysis. Lancet 2002;360:1131-5.

9 Deloitte National E-Health and Information Principal Committee. National E-health strategy [document on the Internet]. 2008 [cited 2010 June 13]. Available from: http:// www.health.gov.au/internet/main/publishing.nsf/Content/604CF 066BE48789DCA25751D000C15C7/\$File/National $\% 20$ eHealth $\%$ 20Strategy $\% 20$ final.pdf.

10 Van De Belt TH, Engelen LJ, Berben SA, Schoonhoven L. Definition of Health 2.0 and Medicine 2.0: a systematic review. J Med Internet Res 2010;12:e18.

11 Khor Z, Marsh P. Life online: the web in 2020. Oxford: The Social Issues Research Centre; 2006.

12 Berners-Lee T, Fischetti M. Weaving the web: the original design and ultimate destiny of the world wide web by its inventor. San Francisco (CA): Harper; 1999.

13 Norman CD, Skinner HA. Engaging youth in e-health promotion: lessons learned from a decade of TeenNet research. Adolesc Med State Art Rev 2007;18:357-69.

14 Wantland D, Portillo C, Holzemer W, Slaughter R, McGee E. The effectiveness of web-based vs non-web-based interventions: a meta-analysis of behavioural change outcomes. J Med Internet Res 2004;6:e40.

15 Kerr C, Murray E, Stevenson F, Gore C, Nazareth I. Internet interventions for long-term conditions: patient and caregiver quality criteria. J Med Internet Res 2006;8:e13.

16 McGuire R. Examining intervention components for promoting adherence to strength weight training exercise in postmenopausal breast cancer survivors with bone loss. Omaha (NE): University of Nebraska Medical Centre: 2008.

17 Wilbur J, Vassalo A, Chandler P, McDevitt J, Miller AM. Midlife women's adherence to home-based walking during maintenance. Nurs Res 2005;54:33-40.

18 Meigs JB, Cagliero E, Dubey A, Murphy-Sheehy P, Gildesgame C, Chueh $\mathrm{H}$, et al. A controlled trial of web-based diabetes disease management: the $\mathrm{MGH}$ diabetes primary care improvement project. Diabetes Care 2003;26:750-7.

19 Alexander GL, McClure JB, Calvi JH, Divine GW, Stopponi MA, Rolnick SJ, et al. A randomized clinical trial evaluating online interventions to improve fruit and vegetable consumption. Am J Public Health 2010;100:319-26.

20 Hohenadel J, Kaegi E, Laidlaw J, Kovacik G, Cortinois A, Kang R, et al. Leveling the playing field: the personal coach program as an innovative approach to assess and address the supportive care needs of underserved cancer patients. J Support Oncol 2007;5:185-93.

21 Graham AL, Abrams DB. Reducing the cancer burden of lifestyle factors: opportunities and challenges of the internet. J Med Internet Res 2005;7:e26.

22 Lorig KR, Ritter PL, Laurent DD, Plant K. Internet-based chronic disease self-management: a randomized trial. Med Care 2006;44:964-71.

23 Spittaels H, De Bourdeaudhuij I, Vandelanotte C. Evaluation of a website delivered, computer-tailored intervention for increasing physical activity in the general population. Prev Med 2007; 44:209-17.

24 Atkinson NL, Saperstein SL, Pleis J. Using the internet for health-related activities: findings from a national probability sample. J Med Internet Res 2009;11:e4.

25 Norum J, Grev A, Moen MA, Balteskard L, Holthe K. Information and communication technology (ICT) in oncology. Patients' and relatives' experiences and suggestions. Support Care Cancer 2003;11:286-93.

26 Gustafson DH, Hawkins R, Pingree S, McTavish F, Arora NK, Mendenhall J, et al. Effect of computer support on younger women with breast cancer. J Gen Intern Med 2001;16:435-45.

27 Kinnane NA, Milne DJ. The role of the internet in supporting and informing carers of people with cancer: a literature review. Support Care Cancer 2010;18:1123-36.

28 Murrat E, Burns J, See TS, Lai R, Nazareth I. Interactive health communication applications for people with chronic disease. Cochrane Database Syst Rev 2005;4:CD004274.

29 Gysels M, Higginson IJ. Interactive technologies and videotapes for patient education in cancer care: systematic review and meta-analysis of randomised trials. Support Care Cancer 2007; 15:7-20.

30 Bylund CL, Gueguen JA, Sabee CM, Imes RS, Li Y, Sanford AA. Provider-patient dialogue about internet health information: an exploration of strategies to improve the providerpatient relationship. Patient Educ Couns 2007;66:346-52. 
31 Helft PR, Hlubocky F, Daugherty CK. American oncologists' views of internet use by cancer patients: a mail survey of American Society of Clinical Oncology members. J Clin Oncol 2003;21:942-7.

32 Bright MA, Fleisher L, Thomsen C, Morrad ME, Marcuse A, Gehring W. Exploring e-health usage and interest among cancer information service users: the need for personalized interactions and multiple channels remains. J Health Commun 2005; 10:35-52.

33 Hacker ED. Technology and quality of life outcomes. Semin Oncol Nurs 2010;26:47-58.

34 Hesse BW, Hanna C, Massett HA, Hesse NK. Outside the box: will information technology be a viable intervention to improve the quality of cancer care? J Natl Cancer Inst Monogr 2010;2010:81-9.

35 Baker L, Wagner TH, Singer S, Bundorf MK. Use of the internet and e-mail for health care information: results from a national survey. JAMA 2003;289:2400-6.

36 Pandey M, Thomas B. Rehabilitation of cancer patients. J Postgrad Med 2001;47:62-5.

37 Gustafson DH, Hawkins RP, Boberg EW, Bricker E, Pingiree S, Chan CL. The use and impact of a computer-based support system for people living with AIDS and HIV infection. Proc Annu Symp Comput Appl Med Care 1994:604-8.

38 Zilliacus EM, Meiser B, Lobb EA, Kirk J, Warwick L, Tucker K. Women's experience of telehealth cancer genetic counselling. J Genet Couns 2010;19:463-72.

39 Neuhauser L, Kreps GL. Online cancer communication meeting the literacy, cultural and linguistic needs of diverse audiences. Patient Educ Couns 2008;71:365-77.

40 Ziebland S. The importance of being expert: the quest for cancer information on the internet. Soc Sci Med 2004;59:1783-93.

41 Usher W. Gold Coast general practitioners understanding pertaining to reliability, interactive and usability components associated with health websites. Behav Inform Technol 2009;28:39-44.

42 Vital Wave Consulting. mHealth for development: the opportunity of mobile technology for healthcare in the developing world. Washington DC and Berkshire: UN Foundation and Vodafone Foundation Partnership; 2009.

43 Chou WS, Hunt YM, Beckjord EB, Moser RP, Hesse BW. Social media use in the United States: implications for health communication. J Med Internet Res 2009;11:e48.

44 Bielli E, Carminati F, La Capra S, Lina M, Brunelli C, Tamburini M. A wireless health outcomes monitoring system (WHOMS): development and field testing with cancer patients using mobile phones. BMC Med Inform Decis Mak 2004;4:7.
45 Maguire R, McCann L, Miller M, Kearney N. Nurse's perceptions and experiences of using a mobile-phone-based advanced symptom management system (ASyMS) to monitor and manage chemotherapy-related toxicity. Eur J Oncol Nurs 2008;12:380-6.

46 Kreps GL, Neuhauser L. New directions in eHealth communication: opportunities and challenges. Patient Educ Couns 2010;78:329-36.

47 Kreuter M, Wray R. Tailored and targeted health communication: strategies for enhancing information relevance. Am J Health Behav 2003;27:227-32.

48 Marcus A, Mason M, Wolfe P, Rimer B, Lipkus I, Strecher V, et al. The efficacy of tailored print materials in promoting colorectal cancer screening: results from a randomized trial involving callers to the National Cancer Institute's Cancer Information Service. J Health Commun 2005;10:83-104.

49 Smeets T, Brug J, de Vries H. Effects of tailoring health messages on physical activity. Health Educ Res 2008;23:402-13.

50 Strecher V, Shiffman S, West R. Randomized controlled trial of a web-based computer-tailored smoking cessation program as a supplement to nicotine patch therapy. Addiction 2005;100:682-

51 Williamson D, Walden H, White M, York-Crowe E, Newton Jr R, Alfonso A, et al. Two-year internet-based randomized controlled trial for weight loss in African-American girls. Obesity 2006; 14:1231-43.

52 Demiris G. The diffusion of virtual communities in health care: concepts and challenges. Patient Educ Couns 2006;62:178-88.

53 Petticrew M, Bell R, Hunter D. Influence of psychological coping on survival and recurrence in people with cancer: systematic review. BMJ 2002;325:1066.

54 National Breast Cancer Centre and National Cancer Control Initiative. Clinical practice guidelines for the psychosocial care of adults with cancer. Sydney (NSW): National Breast Cancer Centre; 2003.

55 Jones R, Pearson J, McGregor S, Cawsey AJ, Barrett A, Craig N, et al. Randomised trial of personalised computer based information for cancer patients. BMJ 1999;319:1241-7.

56 Murray E, Khadjesari Z, White IR, Kalaitzaki E, Godfrey C, McCambridge $\mathrm{J}$, et al. Methodological challenges in online trials. J Med Internet Res 2009;11:e9.

57 Elkin EB, Bach PB. Cancer's next frontier: addressing high and increasing costs. JAMA 2010;303:1086-7.

58 Atienza AA, Hesse BW, Gustafson DH, Croyle RT. e-health research and patient-centered care. Examining theory, methods, and application. Am J Prev Med 2010;38:85-8. 